\title{
IMAGEN DE NICARAGUA \\ EN LA LITERATURA IMPERIAL: EXPLORACIÓN, CONQUISTA, COLONIZACIÓN
}

\author{
Por \\ ILEANA RODRIGUEZ \\ University of Minnesota
}

El siglo XVI fue testigo del nacimiento de una literatura que, en diversas formas y géneros, hablaba de la existencia de un NOVO ORBE. Esta literatura testimoniaba el proceso histórico trascendental que puso involuntariamente en contacto un conjunto de grupos humanos, heterogéneos en sus modos culturales y múltiples en sus momentos de desarrollo económico y formación social. La historia de las letras nicaragüenses encuentra en ella su primera expresión.

Las primeras noticias testimoniales que tenemos de este territorio datan de 1503, fecha del cuarto viaje de Colón a América. De ahí en adelante se suceden un número determinado de documentos; y para el último tercio del siglo, ya bien avanzado el proyecto de colonización, los exploradores, conquistadores y cronistas mayores y menores han dedicado por lo menos unas cuantas páginas a esta región. Entre los más destacados que ofrece el caso de Nicaragua, podemos mencionar a Cristóbal Colón (1503), a Gil González Dávila (1524), a Pedro Mártir de Anglería (1524), a Pascual de Andogoya (1545-46), a fray Bartolomé de las Casas (1535), a Gonzalo Fernández de Oviedo (1526-57). Entre los cronistas importantes que dedicaron algunas breves páginas a Nicaragua se encuentran Francisco López de Gómara (1551), Girolano Benzoni (1565), Fray Toribio de Benavente (1585). ${ }^{1}$ Además de éstos podemos mencionar un gran número de cartas oficiales que circularon entre la provincia de Nicaragua y España,

1 El trabajo de recopilación de documentos del siglo XVI más completa que se ha hecho en Nicaragua se debe al esfuerzo de Andrés Vega Bolaños. En el siglo XIX, Manuel M. de Paralta también llevó a cabo un buen trabajo de recopilación de documentos. Otra fuente necesaria es la obra de Martín Fernández de Navarrete. Recientemente en Nicaragua contamos con el trabajo hecho por Jorge Eduardo Arellano y Eduardo Pérez-Valle. (Ver Andrés Vega Bolaños, Documentos para la Historia de Nicaragua. Madrid: Colección Somoza, 1954-56; Manuel M. de Peralta, ed. Costa Rica, Nicaragua y Panamá en el siglo XVI. Su historia y sus límites según los documentos del Archivo de Indias de Sevilla, del de Simancas, etc. Madrid: Librería de M. Murillo. 1883; Martín Fernández de Navarrete, ed. Colección de Viajes y Descubrimientos. Madrid, 1954; Jorge Eduardo Arellano, ed. Nicaragua en los cronistas de Indias. Managua: Banco de América, 1975; Eduardo Pérez Valle, ed. Nicaragua en los cronistas de Indias - Oviedo. Managua: Banco de America, 1977). 
entre ellas las de Pedrarias Dávila, Diego López de Salcedo, etc., ${ }^{2}$ y otro grupo de textos ingleses anómimos, de gente que exploró también nuestra Costa Atlántico/Caribe. ${ }^{3}$ En estas colecciones de documentos hallan respuesta muchas interrogantes planteadas por la problemática nacional.

Los cronistas mencionados pertenecen a diversos momentos del proceso de amalgamación inter-cultural, que empieza con la exploración, continúa con la conquista y termina con la colonización. Estos momentos o etapas, además de traslaparse, son de corta duración. El primero abarca de 1503 a 1524 y comprende el período exploratorio de la costa - Atlántico/Caribe, y de la costa del Pacífico. El segundo, de 1524 a 1535, consolida la conquista e inicia pero no cimenta el proceso de colonización. El tercero, que arranca de 1535 , patentiza que la temprana época colonial ha comenzado.

Hacia la tercera década del siglo, entonces, estas letras testimoniales cambian perceptiblemente de giro. Al carácter épico, heroico de los primeros documentos, sucede la prosa complaciente de Oviedo y el tono indignado del manifiesto de Las Casas proponiendo formas alternas de colonización, y éste a su vez, da paso al tono más reposado de la época posterior que indica que la vida sedentaria de la colonia ha empezado. Pero la prosa de Oviedo y las Casas ya caracteriza la temprana época colonial.

Los cronistas se dividen en mayores y menores según sea el grado de interés y dedicación que hayan ofrecido a la provincia de Nicaragua. Entre los menores encontraremos gente de gran renombre cuyo aporte a Nicaragua es sólo tangencial. Es más, su testimonio se limita a repetir o a comentar los textos clásicos sobre esta provincia.

En este trabajo ofrecemos los contornos estilísticos de las letras imperiales: (exploración, conquista, colonización), producidas entre los años 1503-1535, intentando 1) identificar los rasgos genéricos más sobresalientes de esta narrativa; 2) trazar las raíces ideológicas implícitas en su tema y en su estilo; 3) deslindar la etapa de la exploración y la conquista de los primeros años de la colonización.

Este planteamiento, espero, nos permitirá a la vez desbrozar ciertas cuestiones ideológicas determinantes en la producción literaria e importantes para un entendimiento de la metodología crítica cultural. Entre ellas algunas urgentes tales como el conjunto de preguntas concernientes al origen, función y formación de los géneros literarios y a su carácter puro o

2 Ver Manuel Paralta, Costa Rica, Nicaragua...

3 Ver N.W., "The Mosqueto Indian and his Golden River; being a familiar Description of the Mosqueto Kingdom in America, with a relation of the Strange Customs, Religion, wars, etc. of those heathenish People." (En Churchill Awnsham, A Collection of Voyages... Vol. 6., London, 1744, pp. 299-312). 
mixto; la periodización sui generis y el carácter regional de las letras de esta zona Centro-Caribe, en las cuales se inserta naturalmente Nicaragua; y finalmente, la producción literaria como creación grupal -más tarde de clase-, organizada álrededor de ciertos núcleos de interés, cuyas leyes y lineamientos extra-literarios hay que destacar.

El propósito general es subrayar el enfrentamiento entre Orbe Nuevo y Orbe Viejo, la participación determinante del aborigen en el proyecto mismo de colonización, $y$, por ende, en la formulación conceptual de un Nuevo Mundo Híbrido. Aprovechamos además la oportunidad de trazar las raíces de numerosos malentendidos ideológicos que tienen su origen en este primer encuentro.

\section{ESTILO LITERARIO/NECESIDAD MERCANTIL-RASGOS GENERICOS COMU-} NES

Los primeros europeos que navegaron nuestros mares, vieron nuestras costas, penetraron nuestras tierras, formaban directa $o$ indirectamente parte del esquema europeo de expansión imperial. ${ }^{4}$ Financiados en sus diversos momentos por la variada conjugación del capital privado, el estatal y las casas comerciales, los viajes de exploración y conquista estuvieron además sujetos a las leyes mercantiles que regían la época, y fueron por ende computados como riesgos comerciales. ${ }^{5} \mathrm{La}$ literatura producida en esta coyuntura no nació, por supuesto, al margen de la poderosa fuerza socio-económica de este programa imperial, sino que, por el contrario, estuvo ligada a él desde el primer momento. La coincidencia de ciertos rasgos genéricos (tema/estilo), comunes a todo este corpus literario, hace suficientemente explícita esta ligazón.

Describir y detallar las porciones territoriales a las que el ingenio y poder europeo daban acceso, fue entonces la primera condición que la economía política del mercantilismo impuso a esta literatura. La descripción y el detalle eran condiciones sine qua non, porque ellas informaban sobre las riquezas reales o potenciales de un intercambio comercial tan beneficioso cuanto desigual. Pero, a más de informar, los documentos dejan entrever muchas otras funciones: ellos tuvieron un valor legal, porque describiendo, prácticamente aseguraban la toma de posesión de lo descubierto. Mediante la información detallada, adornada y exagerada, la empresa privada reclamó sus dividendos, ora cobrando de antemano los gastos invertidos,

4 Ver Mario Góngora, Studies in the Colonial History of Spanish America. (Cambridge, Cambridge University Press, 1975. pp. 5 y siguientes). Desafortunadamente sólo hemos contado con la traducción inglesa de este texto originalmente escrito en español.

5 Ver Carlos Meléndez, Hernández de Córdoba: Capitán de Conquista en Nicaragua. (Managua: Banco de America, 1976). pp. 25-26. 
ora pidiendo gubernaturas. También los estados nacionales se sirvieron de ellos. Cuando Inglaterra, Francia y Holanda disputaron a España el derecho de ocupación exclusiva de las tierras americanas, los documentos de exploradores y viajeros se tradujeron a varias lenguas para servir de base al derecho internacional. ${ }^{6}$

Si aceptamos que estas necesidades mercantiles -económicas, políticas y sociales- constituyen el trasfondo de la literatura en esta primera época, comprenderemos los rasgos esenciales de su estilo y de su carácter grupal. En ellas puede encontrar explicación el origen y formación de los géneros literarios peculiares a nuestra región, tanto como el entendimiento de su función social. ${ }^{7}$ En su madrugar literario se enraízan, como ya veremos, las peculiaridades de la cronología sui generis de las letras del área.

Lo que aquí venimos exponiendo explica tal vez por qué el rasgo temático sobresaliente de los textos de los primeros cronistas sea, sin duda, su insistente y marcada obsesión geográfica, unida, por supuesto, a la búsqueda del oro. Casi todos ellos empiezan por describir los contornos del territorio que ven y pisan por primera vez. Abundan en ellos las referencias a oriente y occidente, a norte y sur. A los puntos cardinales se unen la longitud y latitud recorridas. Con suma precisión pretenden ellos detallar mares, islas, rios, lagunas, cayos, esteros, montañas, penínsulas, golfos. La naturaleza y sus riquezas vegetales, flores y frutos, minerales, completan el cuadro de la visión geográfica, natural, que iba por primera vez a dar a conocer, en forma escrita, nuestro continente. Esta primera visión circulante es por tanto esencial al pensamiento y conceptualización que a partir del siglo XVI, el europeo hace del NOVO ORBE. El primitivismo, el exotismo, el racismo tendrán ahí sus raíces.

Adherida a ella, en su primer momento, se nos revelan sumariamente otros tópicos narrativos: los encuentros grupales hispano o angloindígenas, las divisiones territoriales de los aborígenes, su cultura y civilización, y finalmente, un muy, pero muy precario, indirecto y selectivo esbozo de su organización social y de la estructura básica de su sistema económico.

A medida que avanza la exploración y se inicia la conquista, los espacios narrativos van variando. El dominio de la geografía en el periodo exploratorio cede el lugar a la descripción selectiva de los conflictos intergrupales durante la conquista, y este último, a la recopilación sumaria de la cultura y civilización de los grupos humanos, con los cuales los

6 Ver Mario Góngora, Studies in the Colonial History..., p. 21 y siguientes.

7 El teórico que ha propuesto este planteamiento en un artículo seminal es Roberto Fernández Retamar. Para una teoria de la literatura hispanoamericana y otras aproximaciones. (La Habana: Cuaderno de Casa de las Américas No. 16, 1975). 
españoles debían desde ese momento convivir, ya iniciada la temprana época colonial.

Pero la literatura de expansión imperial no sólo fue escribiendo el texto europeo. Fundamentálmente nutrida y alimentada por el espacio indígena, se ocupó también de redactar el sub-texto aborigen. Texto y subtexto contribuyen a la formación de la visión americana-que será americanista y nacional después-, compuesta por la amalgama de la historia aborigen/europea en sus primeros encuentros y acomodos. Esta amalgama es discernible en la descripción directa, en lo que perciben y sienten los europeos, pero también y más principalmente en la indirecta; es decir, en lo que censuran, esconden, reordenan, reconceptualizan, procesando las visiones y experiencias de aquellos que, habiendo vivido esto por espacio de siglos, y acostumbrados a su cotidianeidad, habitaban sólo un $O R B E$ VECCHIO.

Razones de orden extra-literario, cuya fuerza radica en la economía política del mercantilismo, subordinaron el sub-texto del mundo viejo de los indígenas, y expandieron y validaron la visión nueva del texto español, haciéndola hegemónica. Como veremos más adelante, la visión mercantil dominante, oscurece, subordina el aporte indígena, casi al punto de hacerlo invisible. Por eso es menester una lectura diferente, rigurosa, crítica, que vaya casi adivinando e infiriendo lo que los europeos significan sin explicitarlo.

En este tipo de lectura vamos, sí, perfilando los contornos de lo verdaderamente nuevo, de la novedad o novela de este mundo. Destaca en primer lugar al encuentro euro-aborigen; curioso en su primer momento, verdaderamente dramático después. De esta experiencia también resulta la amalgama etno-cultural, lo propiamente americano, el mestizaje o lo creole. ${ }^{8}$ Este largo proceso de aculturación, en el cual se mezclan

$8 \mathrm{El}$ significado de la palabra creole es múltiple. Brathwaite lo conceptúa de la manera siguiente: "La palabra misma parece haberse originado de una combinación de dos palabras españolas, criar... y colono... ella significa un poblador comprometido, uno identificado con el área que va a habitar, uno que ha nacido en el área por poblar aunque no tenga sus ancestros indígenas ahí. En Perú... se usa para referirse a las personas de ascendencia española que nacieron en el Nuevo Mundo, que pertenecían a la clase alta, pero que estaban distíntamente bajo el dominio de sus parientes peninsulares. En Brasil el término se aplicó a los negros nacidos ahí. En Luisiana, el término se aplicó a la población blanca de habla francesa, mientras que en Nuevo Orleans se aplicó a los mulatos. En Sierra Leone, creole se refiere a los descendientes de los ex-esclavos del Nuevo Mundo, Cimarrones y Negros pobres de Inglaterra que se establecieron a lo largo de la costa y especialmente en Freetown, y los cuales forman una élite social diferente de las poblaciones africanas. En linguística, el término se usa para significar pidgin o lenguaje limitado que se ha "indigenizado"; que ha venido a ser el lenguaje de una comunidad idiomática. En Trinidad se refiere principalmente a los descendientes negros de esclavos, para distinguirlos de los inmigrantes hindues (coolies). Cuando se usa en referencia a otro grupo nativo, se usa como prefijo adjetival: Francés 
forzosamente las formas económicas, políticas y sociales, es, en definitiva, nuevo, y conforma, dentro del poderoso mercantilismo expansivo de la época, un NUEVO MUNDO HIBRIDO.

Las necesidades económicas infraestructurales (expansión/comercio/oro), generaron, pues, los primeros temas y patrones narrativos. Las necesidades político-sociales dieron pauta a los géneros literarios. Dentro de los temas ya decíamos que la geografía aurífera es preponderante en la primera etapa. En verdad, el oro es el vehículo que promueve el interés, que conduce y facilita el contacto hispano-indígena. Su diferente manera de juzgarlo pone de manifiesto el abismo interpretativo entre ambos mundos. Como objeto económico, el oro es considerado por los europeos como valor de cambio, mientras los aborígenes sólo lo aprecian como valor de uso. En esta compleja formula económica radica en suma el drama indígena y el triunfo europeo.

El tema informa, pues, sobre una geografía productora de oro, a la que se ve con ojos de contador Geiger. El oro define la dirección que ha de tomar la exploración y conquista, guía las miradas inquisitivas de los recién venidos, determinando o por lo menos influenciando su visión, y finalmente mide y cuantifica el tipo de cuestionamiento--preguntas y respuestas-de la interacción euro-aborigen.

Naturalmente el diálogo gira en torno a ese metal y sus yacimientos, que los europeos llaman minas. Los géneros narrativos, ya lo indicábamos anteriormente, vienen de la necesidad de detallar este panorama geográfico y comercial, de fijar el croquis para volver a él, de hacerlo atractivo a los inversionistas y al rey. Todos los géneros y modos narrativos en que se expresa ese momento histórico están, entonces, en tono y carácter infiltrados por la función específica de la prosa de los informes mercantiles y estatales.

Hay sin embargo un género que también aporta su gran contribución a esta amalgama y que no ha sido lo suficientemente resaltado. Nos referimos al género testimonio, que, desde su primer momento, obliga a llamar a esta literatura euro-aborigen. Como veremos más adelante, el conocimiento del territorio registrado en los libros, está trabajado conjuntamente por los exploradores europeos y sus guías indígenas. Los aborígenes aportaron en éste, como en muchos otros aspectos, su contribución, sirviendo de informantes. Acostumbrados al trueque

criollo, Español criollo. En Jamaica... el término se usa en el sentido español original de criollo: nacido en, nativo de, comprometido con el área de residencia, y fue usado en relación a ambos, blancos y negros, libres y esclavos. Ver Edward Brathwaite. Contradictory Omens: Cultural Diversity and Integration in the Caribbean. (Mona: Savacou, 1974, p. 10. La traducción es mía.) 
comercial con los otros grupos aborígenes, y malentendiendo o subestimando la magnitud y fuerza de la empresa europea, empezaron a comerciar con los europeos como lo hacían con los otros grupos humanos. De todos es conocido como les guiaron a sus riquezas, les pusieron en contacto con las otras sociedades indígenas o les dieron noticias de ellas, les tradujeron sus lenguas, les explicaron su sistema de intercambio, e incluso montaron en sus cabalgatas e hicieron posible la conquista.

El proceso de las mezclas se inicia, pues, desde el primer contacto intergrupal, y los testimonios indígenas están presentes desde las primeras páginas escritas sobre estas tierras. Esto nos lleva en sí a modificar una visión que en apariencia, y sólo en apariencia, es exclusivamente geográfica y natural. Ya que ella incluye desde el primer momento lo humano, lo cultural, lo histórico. Por otro lado, ella nos lleva a estudiar y a analizar atenta y rigurosamente aquellas coincidencias conceptuales que lubricaron en el primer encuentro, el contacto, antes de empezar la resistencia a la invasión que ya registra indirecta y sumariamente González Dávila. ${ }^{9}$

Sin embargo el reconocimiento de este aporte cultural a esta expresión literaria, en cuanto expresión aborigen, americana y nicaragüense (en ese estricto orden lógico-temporal), no está excento de problemas. Existen factores mediatizadores que necesitan ser aclarados. Como la misma terminología indica, entre ellos se encuentran prioritariamente los de la nacionalidad, íntimamente ligada a la formación estatal, los de los sistemas de intercambio comercial y los de las manifestaciones culturales.

Resalta de inmediato la discrepancia de los diferentes momentos de desarrollo. Los europeos llegan a estas costas con la forma de intercambio mercantil del naciente capitalismo bien enraizada, con su nacionalidad y estructura estatal formada (son españoles, franceses, ingleses) y se enfrentan con grupos humanos organizados en lo que ellos llaman "tierras", "territorios", y en el mejor de los casos "provincias," - definición propia aplicada-, que luego poblaran de "naturales", "indios", "tribus", para referirse tentativamente en el primer caso a su organización políticoadministrativa, y en el último a la social. Esta nomenclatura inicial nace de un error teórico, que empieza por aplicar el modelo conceptual europeo a lo recién visto, como se puede palpar particularmente en el proverbial concepto de indio (de las Indias) a los indígenas.

En todo caso, lo primero que los europeos vieron fueron tierras y territorios, que luego iban a organizar, siguiendo sus propias divisiones geopolíticas, en provincias, utilizando a la vez que transformando los asentamientos humanos estructurados en cacicazgos. Esta amalgama iba a

9 Ver Manuel Peralta, Costa Rica, Nicaragua... pp. 3-32. 
tal punto a perdurar que en algunos casos como el de Nicaragua nombra posteriormente la unidad nacional.

Si en el terreno geo-político los arreglos fueron mixtos, en el económico la fuerza del intercambio del capital mercantil se impuso sobre el trueque del mercado indígena. Aprovechando la comunicación permitida por el intercambio (productos por mercancías), los europeos se fueron apoderando del surplus indígena y de su fuerza de trabajo. Para esto se preocuparon poco por conocer la producción, el mercado y la cultura indígena, ya que gran parte del encuentro se llevó a cabo por las fuerzas de las armas.

Para nuestro propósito literario importa, sí, recordar que, apoyado por esta fuerza armada, se eradicó del mapa cultural el aporte aborigen codificado, quedando así vencedora la letra sobre la palabra. Levi apunta que en 1524, esto es, recién fundadas las ciudades de León y Granada, el padre Bobadilla llevó a cabo en Managua la famosa quema de los libros, mapas, pinturas y documentos indígenas. ${ }^{10}$ Queda así sellado el destino de la literatura oral, subsumida, como ya indicábamos anteriormente, a la categoría literaria de sub-texto. Es fácil y provechoso sospechar que actos similares al señalado hayan quedado sin registro y que puedan por tanto sólo inferirse y adivinarse en las pocas referencias veladas que de ello hacen los textos.

En todo caso, la solución al problema de la legitimación de lo nuestro en estas primeras expresiones letradas, yace en el reconocimiento de la lucha desigual entre estos momentos diferentes del proceso de desarrollo económico, que lleva a cabo la especie humana. Lucha, añadimos, en que los vencedores harán marcar con sangre a los vencidos, su aporte a la americanidad.

2. DIFERENTES MOMENTOS CRONOLÓGICOS DE UNA NARRATIVA SIMILAR: DOS IMPERIOS, UN GENERO--SUS VARIANTES

Si empezamos por problematizar los rasgos temáticos de estos textos y sus desplazamientos cronológicos, veremos que ellos vienen expresados en un cierto estilo narrativo que les es consustancial. Este estilo revela y esconde una visión utilitaria y mercantil, que desvirtúa y denigra, en diferentes grados y con mayor o menor intensidad, a nuestros ancestros aborígenes, sobre todo en lo que atañe a sus formas culturales y a su organización social.

Los temas dominantes que ya señalábamos anteriormente vienen así acompañados de sus corolarios ideológicos, cuya secuela temático-ideo-

10 Ver Pablo Levi, Notas goegráficas y económicas sobre la república de Nicaragua. (Jaime Incer Barquero, ed. Managua: Banco de América, 1976). p. 7. 
lógica afecta las letras posteriores, a saber: 1) A descripción geográfica, visión del aborigen como "natural", mezclado y confundido con la maleza (más tarde, en los siglos 18 y 19, el personaje evolucionará, vistiéndose de "buen salvaje", protótipo ideal de la transición del mercantilismo al librecambismo; así lo reconoceremos en medio del paisaje pintoresco o ideal del romanticismo). 2) A descripción de la cultura y civilización, visión de la misma como dato de "usos" y "costrumbres" (su escuela es la colocación de la dimensión humana dentro del marco antropológico, y la consecuente negación o soslayamiento del aporte histórico; ahí puede tener su origen la literatura costumbrista). 3) A descripción del asentamiento colonial, visión escamoteada del indígena y surgimiento del tipo híbrido prometedor. (En su primer momento éste aparece rebajado como la mezcla y lo mezclado. Los tipos clásicos son el mestizo, el mulato y el criollo o creole. Su primera expresión es racista: él da su aporte a la literatura romántica, naturalista y de costumbres; pero a la vez él encierra el secreto, la raíz, de la auténtica prosa histórica, escasa pero presente en todos los siglos, si no en forma dominante, al menos como momento bien logrado, como tendencia).

Como hemos mostrado en forma parentética, estos corolarios ideológicos iban a tener una resistencia de siglos, e iban a afectar el desarrollo de nuestras letras, contaminándolas con una visión negativa, auto-degradante de nuestra identidad, en sus diferentes versiones y modalidades. Esta es en concreto la herencia ideológica que nos legaron las primeras letras. Por eso conviene trazar las ligazones y desfasamientos entre tema, estilo, ideología y género narrativo, así como identificar ejemplos de momentos productivos, que en esta zona marcan disparidades y variantes de sumo interés, entre, digamos, el producto letrado colonialista inglés y el español.

De hecho, el contrapunto narrativo que ofrecen las letras españolas e inglesas respecto a la zona Centro-Caribe en general, y Nicaragüense en particular, nos lleva necesariamente a inquirir sobre las razones que obedece la temática señalada, tan uniforme y persistente, que va trazando firmemente el perfil ideológico de los diferentes momentos narrativos, de sus conjuntos génericos, expresados en momentos históricos dispares. A la vez nos permite señalar sin pretensiones ni mascaradas, ya la influencia decisiva que nosotros hemos ejercido en las letras europeas, ya el cuestionamiento de la nacionalidad de esas mismas letras.

En páginas anteriores habíamos sugerido que las coincidencias narrativas de fondo y forma de la literatura imperial obedecían a un conjunto de razones peculiares al momento del desarrollo de la economíapolítica del capitalismo de los siglos XVI y XVII. Este desarrollo involucra como ya veremos más adelante, las luchas inter e intra 'zonales' Europeas y Americanas, cuyo núcleo conflictivo candente se encuentra situado en el 
área Centro-Caribe, en la cual Nicaragua ocupa una posición clave. ${ }^{11}$ No en balde el padre las Casas la llamaba "médula y riñonada de todas las indias". Prueba de ello la encontramos además en el presente siglo en la escisión territorial Costa Atlántica-Caribe/Costa del Pacífico (que en algunas regiones-Belize, Guyanas-creó naciones y nacionalidades), legado histórico de la influencia determinante de los conflictos europeos en nuestros territorios, los cuales se encuentran relatados en los textos de estos primeros cronistas epañoles e ingleses.

Nos encontramos así ante la presencia de un grupo de textos españoles escritos alrededor de 1503-1535, que muestran similitudes formales con textos ingleses anónimos del siglo XVII y entre los cuales nosotros contamos con una de 1699, que aquí nos proponemos utilizar como modelo. ${ }^{12}$ Este texto trata de la exploración inglesa de la Mosquitia. Lo que primero se nos ocurre constatar, a casi dos siglos de distancia que median entre los primeros y los últimos, son las semejanzas temáticas, estílisticas de los textos en cuestión. Esto es, ya cuando los españoles habían avanzado considerablemente en el proceso del mestizaje etnocultural, al grado de haber poblado y fundado ciudades, creado sociedades, es cuando los ingleses empiezan a disputarles, en forma abierta y agresiva, el poder - recuérdese que la fundación de Jamaica data de esa época-, e inician el proceso del mestizaje indo/negro/blanco que se conoce hoy en día bajo el nombre de creole. En Nicaragua concurren así ambos tipos de amalgama, la mestiza y la creole.

El documento inglés que nosotros tenemos a la mano, ya decíamos, data de 1699. El establece la ligazón entre imperio e imperio, entre islas del Caribe y tierra centroamericana en la llamada Costa Atlántica Nicaragüense (único punto en el que la simbiosis se realiza sin ruptura nacional), y traza la indisolube continuidad genérica de una literatura mercantilista, producida prácticamente por encargo, o nacida de las necesidades oficialistas del estado en su empresa imperial. Sus temas y estilo, por tanto, se corresponden.

La separación de dos siglos que media entre los manuscritos aquí en cuestión, marca, entonces, el desplazamiento del poderío imperial de España a Inglaterra, que va a venir a culminar en el siglo XIX. Estos parámetros socio-políticos, estos estudios de desarrollo europeo y sus alineamientos, tienen mucho que ver con la producción literaria; a ellos se

11 En general no hay historiador del área que no enfatice la importancia estratégica de Nicaragua en la zona Centro-Caribe y su viabilidad natural para la construcción del canal. El último historiador en mencionar este dato es Jaime Wheelock, Imperialismo y Dictadura: crisis de una formacion social. (Mexico: Siglo XXI, 1975).

12 Ver Eduardo Pérez-Valle, Expediente de campos azules: Historia de Bluefields en sus documentos. (Managua, 1978). 
pueden referir las raíces funcionales de un estilo y un género, perceptibles apenas en los sutiles desfasamientos de la prosa de estos documentos.

Adelantemos por el momento unas observaciones pertinentes que desarrollaremos más 'tarde. En primer lugar la distancia cronológica. El hecho de que hayan transcurrido casi dos siglos entre una y otra empresa mercantil y literaria, otorga a los ingleses la ventaja de la apropiación de la experiencia acumulada por los españoles. Así, mientras los primeros vinieron a poblar, a establecer colonias, los segundos venían sólo a explorar, a ver si podian producir formas alternas de control y asentamientos, formas similares, quizás, al incipiente modelo neo-colonial, del cual pueden ser muestras intermedias el absentismo característico de las sociedades plantócratas inglesas de las islas. ${ }^{13}$

Este modelo que todavía se inserta en el mercantilismo, pero ya va, sin embargo, rumbo al librecambismo, va a tener su correlativo en el género literario. El caso inglés, como el español, produce primero que nada documentos exploratorios, de ahí la importancia de la geografía como topoi literario. Pero la literatura inglesa en Nicaragua (no así la de las islas), no pasa por los diferentes momentos narrativos que pasa la española, y que ya indicábamos con anterioridad, sino que, por el contrario, parece que sintetiza en este texto, todos ellos. Por eso es, quizás, que el texto inglés tiene ya más el carácter de libro de viajero que el de crónica, tendencia que no faltaba en los primeros, pero que estaba atenuada por el testimonio del encuentro y debate con los aborígenes, por la fundación de ciudades, propia a su proyecto colonial. En cambio el documento inglés, fiel a su modelo de colonización, sólo señala asentamientos accidentales y fortuitos, muy a la manera de Robinson Crusoe, personaje cuyos antecedentes abundan en esta narrativa de la cual hablamos aquí. Hay en ella por lo menos un par de ingleses, regados en las márgenes del rio Coco (Wanka), que se fueron quedando en este territorio por accidente, porque los olvidó su barco, porque éste naufragó, o por crímenes cometidos en las islas y viven ahí entonces, muy a la manera de aquel héroe de novela. ${ }^{14}$

Podría sugerirse que el modelo de colonización, o de explotación, y su coyuntura histórica, tienden a producir modos y géneros narrativos diversos, o a acentuar las tendencias. En nuestro caso vemos que el libro de viaje, género tan cultivado por las letras inglesas, domina ya en este manuscrito. Dentro de esta tendencia, natural es que abunden los

13 Ver Philip Curtin, Two Jamaicas: The Role of Ideas in a Tropical Colony, 1830-1865. (New York: Atheneum, 1975); Lowell J. Ragatz, The Fall of the Planter Class in the British Caribbean, 1763-1833. (New York, 1928).

14 El que se ha interesado más en este tema es Pablo Antonio Cuadra, El Nicaragüense. (Costa Rica: Educa, 1978), pp. 81-89. 
personajes a la Robinson; pero en ellas también abunda otro personaje que hay que rescatar, el esclavo negro y el cimarrón-dos versiones distintas de una misma realidad. El usufructo del oro blanco (el azúcar), había traído a nuestras costas el tráfico de esclavos, y la resistencia al mismo, fue dejando en su ruta alguno que otro cimarrón resistente. Ellos empezaron el proceso de creolización, realizando las mezclas indo-africanas.

La importancia de la existencia de estas variantes temáticas y estilísticas en el documento inglés es que ellas conducen a deslindes semánticos e ideológicos de gran importancia para el esclarecimiento de los géneros y de las transiciones entre uno y otro, a la vez que van dando cuenta de los cambios observables en el desarrollo social, económico de las naciones europeas en relación con nuestras tierras. Como lo van revelando las formas narrativas, los ciclos de desarrollo son parecidos pero no idénticos. El aspecto exploratorio es similar en ambos; los patrones de asentamiento, en cambio, no pueden ser más divergentes. La meta, la extracción del surplus, es idéntica, la coyuntura de su explotación diversa. De ahí las semejanzas de los parámetros estilísticos y de ahí también sus divergencias.

\section{RASGOS ESTILISTICOS Y FORMAS NARRATIVAS DIALECTALES}

Las variantes que veníamos anotando en el inciso anterior no obstan para que identifiquemos en estas formas narrativas dialectales el lenguaje común. Entre los rasgos estilísticos similares que hemos logrado separar se encuentran los siguientes:

1) Una absoluta confusión de los puntos de referencia geográficos que van marcando, supuestamente, los contornos de un Nuevo Mundo. El desconocimiento del terreno va creando una visión confusa que se apega más a las reglas del juego de la ficción, que a las de la cartografía científica. Entre sus ejemplos más significativos podemos mencionar los siguientes: el Pacífico es el Mar del Sur y el Atlantico el Mar del Norte-u occidental para los europeos, lo que lo hace oriental para nosotros; el lago de Granada (Cocibolca para los indígenas), es el Mar de Agua Dulce; el desaguadero es el estrecho que conecta el océano Atlántico (Mar del Norte) con el océano Pacífico (Mar del Sur), por medio del Lago de Granada (Cocibolca o Mar de Agua Dulce). ${ }^{15}$ La Tierra Firme, cuyo primer punto colonizado y poblado es la actual Panamá, se llama El Darién, luego se creó la provincia de Castilla de Oro. El que inaugura esta geografía fantaseosa es por supuesto Colón, pero el texto inglés, mucho más científico y exacto, no deja de caer en ella.

15 Ver Eduardo Pérez Valle, El desaguadero de la Mar Dulce. (Managua: Banco de América, 1977). El autor trata de establecer orden y coherencia en un enredo de datos y referencias típicas de la prosa narrativa de esos siglos. 
2) Esta confusión geográfica está agravada por una visión cuantificadora, manifiesta en la insistencia de dar pesos y medidas. Abundan en ellas referencias a la longițud y latitud, a lo largo y lo ancho, a lo próximo o lo lejano, a lo grande o lo pequeño. Usando estos mismos términos vagos se llega al extremo de acudir a nombrar los puntos de referencia con frases tales como "el último confín", "el creído continente", "el estrecho dudoso".

3) Además, la descripción geográfica no es consistente y ordenada, sino que salta de un punto geográfico a otro sin solución de continuidad y sin hilván lógico. Por ejemplo no sabemos como pasa Gil González del Atlántico al Pacífico; su ruta por Honduras es totalmente imaginaria. No sabemos las rutas del grupo de Hernán Cortés que bajó hasta Nicaragua.

4) Esta confusión, que no se aplica sólo a la geografía, pero que encuentra su mejor expresión en ella, se ve agravada por una sintaxis a menudo confusa, que se traduce en una puntuación equívoca (no siempre consistente en sus patrones y variantes), en una serie de oraciones incompletas, en una constante subordinación de cláusulas en las cuales la hilera de pronombres relativos-quien, que, cuyo, dicho-al ponerse en cadena tienden a perder el referente o nombre al cual substituyen. Este estilo se verá continuado en el pasaje de la geografía a las costumbres, el cual se caracteriza por los hiatos en los diálogos-o por la supresión de los mismos-por la incapacidad de recreación de los escenarios donde se llevan a cabo los bautizos, y deposiciones e interrogatorios, y por los clásicos non sequitur entre un párrafo y otro. Esta sintaxis confusa y mal alineada es una de las indicaciones más urgentes y desnudas de la clase social de los narradores.

5) La relativización de la objetividad, que alcanza un óptimo en las frutas y verduras, en los aspectos geográficos localizados, como los volcanes y los rios, y un mínimo en los grupos humanos y su cultura, los cuales son tratados prácticamente en forma aséptica. Esta relativización produce descripciones híbridas, en las que objetividad y subjetividad se mezclan. Tal sucede principalmente en la descripción de productos agrícolas, i.e., de aquéllos que no se dan espontáneamente, sino que requieren el concurso humano para su producción, y que implican por ende un uso mas "industrializado", más procesado. Palpamos esto por ejemplo en la descripción del maíz y el cacao, pero también en las descripciones de los areítos, y en el recuento de la distribución de la población en ciudades. Suponemos que el cruce de riqueza natural con producción social dentro de un sistema económico dado, causa estos desplazamientos. 
6) Esfuerzo por alcanzar un punto medio, una justicia narrativa, lográndolo sólo a medias. También este aspecto tiene sorpresas en la medida en que hay muchísimas descripciones de costumbres como las de Anglería y Andagoya-y aun las del mismo inglés-que escasamente adjetivan. A no ser un ocasional "horrible", presente al principio y al final del párrafo, el resto es narrado a manera de hechos dados o consumados, muy a la usanza de un empirismo temprano.

7) Desfasamientos conceptuales y sugerencias que nos permiten especular acerca del sistema económico social de los aborígenes, los diferentes grupos sociales, su rasgos culturales, sus mezclas y sobre todo, lo que es más interesante, el concepto de "apertura o receptividad", que permite la inserción y aceptación del elemento europeo en la cultura aborigen. Estas aperturas alcanzan un óptimo en coincidencias como la creencia en el diluvio, o en creencias sobrenaturales inexplicables, que permiten el traslape de religiones en actitudes y conceptos-tal la conjunción de demonio/bruja en el supuesto ser que sale del volcán Masaya. Donde la tela se diluye y el hilo conductor prácticamente se corta, es en la visión de los sacrificios humanos y en la justificación de su práctica. Parece que la idea del desarme también encuentra resistencia y amenaza ruptura, pero éste está escasamente reportado. En este aspecto el texto inglés encuentra variaciones dignas de notar ya que cubre la costa Atlántica/Caribe.

8) Imprecisiones terminológicas, que ponen de manifiesto una confusión conceptual. Ellas marcan las diferencias entre lo nuevo y lo viejo tendientes hacia lo híbrido. En lo geo-político sobresalen términos como región, área, provincia, tierra y sus usos cruzados e indistintos; en lo étnico cultural, la distinción entre indios y caciques, entre indios y negros, y la más interesante que surgirá más tarde entre indios e indianos. Hasta esta fecha no aparece todavía el mestizo, pero si alguien reviste una función de importancia es el "lengua"-nombre de los traductores-, por razones obvias.

9) La exageración como medio de expresar lo nuevo, lo nunca visto, pero también como medio de vender el producto adquirido, de darse gloria, de aumentar y agrandar el carácter épico de la empresa. Estos usos $\mathrm{y}$ funciones distintivas son a veces indistinguibles en el texto.

10) Las constantes - como el volcán Masaya - que van formando una visión casi-turística de la región. Otras son la cantidad de oro recibida, la narración de las disputas intergrupales desde ángulos diferentes-que ayuda y fortalece la caracterización-, la credulidad aborigen inexplicada, la rendición espontánea, los bautizos en masa, los trueques y regalos, el 
diálogo con Nicaragua, los sacrificios humanos, sus casas, ciudades, ricas tierras y productos. Estos tópicos constantes aquí señalados constituyen también núcleos narrativos. A partir de ellos se genera toda una concepción.

Como ya apuntábamos en párrafos anteriores, esta historia en prosa iba a influenciar el desarrollo posterior de la literatura latinoamericana. En la medida que la visión afecta lo visto, la descripción queda también afectada. Como la descripción se premia o se valora en términos de sus aciertos respecto a la naturaleza, ella es la que va a ser desarrollada; en cambio, el escamoteo del indígena va a venir luego a afectar la caracterización tanto física como sicológica de los personajes. La construcción de escenarios y situaciones sufre también en esta narrativa, ya que la grandiosidad natural, la enormidad de la empresa, establece un contraste negativo con la visión de lo humano conquistado. Ambas empiezan a mermar, a tomar una dimensión más cotidiana, a medida que transcurre el siglo. Entonces se empieza a producir un tipo de literatura más apegada a lo americano, y, por ende, diferente.

Estas son, en suma, las peculiaridades narrativas características y clásicas de la literatura imperial-diálogo metropolitano por excelencia, escrito por representantes estatales, o por grupos sociales afiliados o identificados en sus varios grados con el estado. La forma confusa y enredada, la imprecisión geográfica, el énfasis en las medidas, no son características fortuitas, accidentales, sino más bien consubstanciales, ya que ligan esta forma al interés de estos viajeros.

La literatura imperial es pues primero de viajes y viajeros en sus diferentes manifestaciones: exploradores o adelantados, conquistadores, residentes temporales o permanentes. Luego será sedentaria, literatura de veedores, gobernantes coloniales, e incluso simples soldados, grumetes, mayorales. El primer grupo no tiene gran acceso a la educación, o lo tiene parcial, de ahí su sintaxis enredada, su incapacidad conceptual y la determinación clara de sus interes de clase. El segundo cuenta excepciones como Oviedo, Anglería, las Casas, Benzoni. Estos últimos forman parte del grupo de letrados e intérpretes, del grupo se diría de comentadores, que traducen a la lengua europea oficial y diplomática los documentos aquí en cuestión. 
